\title{
ADAPTIVE SLIDING MODE CONTROL FOR BUILDING STRUCTURES USING MAGNETORHEOLOGICAL DAMPERS
}

\author{
Nguyen Thanh Hai ${ }^{(1)}$, Duong Hoai Nghia ${ }^{(2)}$, Lam Quang Chuyen ${ }^{(3)}$ \\ (1) International University, VNU-HCM \\ (2) University of Technology, VNU-HCM \\ (3) Ho Chi Minh Industries and Trade College \\ (Manuscript Received on December $14^{\text {th }}$ 2010, Manuscript Revised August 17 $7^{\text {th }}$ 2011)
}

ABSTRACT: The adaptive sliding mode control for civil structures using Magnetorheological (MR) dampers is proposed for reducing the vibration of the building in this paper. Firstly, the indirect sliding mode control of the structures using these MR dampers is designed. Therefore, in order to solve the nonlinear problem generated by the indirect control, an adaptive law for sliding mode control (SMC) is applied to take into account the controller robustness. Secondly, the adaptive SMC is calculated for the stability of the system based on the Lyapunov theory. Finally, simulation results are shown to demonstrate the effectiveness of the proposed controller.

Keywords: MR damper; structural control; SMC; adaptive SMC.

\section{INTRODUCTION}

Earthquake is one of the several disasters which can occur anywhere in the world. There are a lot of damages to, such as, infrastructures and buildings. This problem has attracted many engineers and researchers to investigate and develop effective approaches to eliminate the losses [1, 2, 3].

One of the approaches to reduce structural responses against earthquake is to use a MR damper as a semi-active device in building control [4-5]. The MR damper is made up of tiny magnetizable particles which are immersed in a carrier fluid and the application of a magnetic field aligns the particles in chain-like structures [6, 7]. The modelling of the MR damper was introduced in [8], and there are many types of MR damper models such as the
Bingham visco-plastic model $[9,10]$, the BoucWen model [11], the modified Bouc-Wen model [12] and many others. In addition, a MR damper model based on an algebraic expression for the damper characteristics is used in the system to reduce the controller complexity [13].

Variable structure system or SMC theory is properly introduced for the structural certainties, such as, seismic-excitation linear structures, non-linear plants or hysteresis [14, 15, 16]. A dynamic output feedback control approach using SMC theory and either the method of LQR or pole assignment control for the building structure was used [17, 18]. Application of SMC theory for the building structures was also found [19]. According to characteristics of MR dampers, SMC are applied for the building structure [20]. 
For the control effectiveness of the systems, it is tackled in this work by means of an adaptive control motivated by the work in adaptive control or adaptive SMC [21, 22, 23, 24]. In this paper, an adaptive law is chosen to apply to SMC such that the nonlinear system is robust and stable on the sliding surface. In addition, the stability of the system is proven based on the Lyapunov function.

The paper is organized as follows. In section 2, the MR damper is described. In section 3 , the indirect control of a building structure model is presented with the equation of motion consisting of nonlinear inputs and disturbances. A SMC algorithm is applied to design the control forces in Section 4. An adaptive SMC is proposed in the system in Section 5. In section 6 , results of numerical simulation for the system with MR dampers are illustrated. Finally, section 7 concludes the paper.

\section{MAGNETORHEOLOGICAL DAMPER}

There are many kinds of MR damper models such as Bingham model, Bouc-Wen model, and modified Bouc-Wen model. However, the MR damper model proposed here has the simple mathematic equations for application in structural control as shown in Fig. 1, [9]. The equations of the MR damper [13] are presented as follows:

$$
\begin{aligned}
& f=c \dot{x}+k x+\alpha z+f_{0}, \\
& z=\tanh (\beta \dot{x}+\delta \operatorname{sign}(x)), \quad(1 \mathrm{~b}) \\
& c=c_{1} i+c_{0}=3.32 i+0.78, \\
& k=k_{1} i+k_{0}=-i+3.97, \quad(1 \mathrm{~d}) \\
& \alpha=\alpha_{2} i^{2}+\alpha_{1} i+\alpha_{0}=-264 i^{2}+939.73 i+45.86,
\end{aligned}
$$
(1e)

$\delta=\delta_{1} i+\delta_{0}=0.44 i+0.48$,

$f_{0}=h_{1} i+h_{0}=-18.21 i-256.50, \quad(1 \mathrm{~g})$

where $i$ is the input current to the MR damper, $f$ is the output force, $z$ is the hysteresis function, $f_{0}$ is the damper force offset, $\beta=0.09$ is a constant against the supplied current values, $\alpha$ is the scaling parameter and $c, k$ are the viscous and stiffness coefficients.

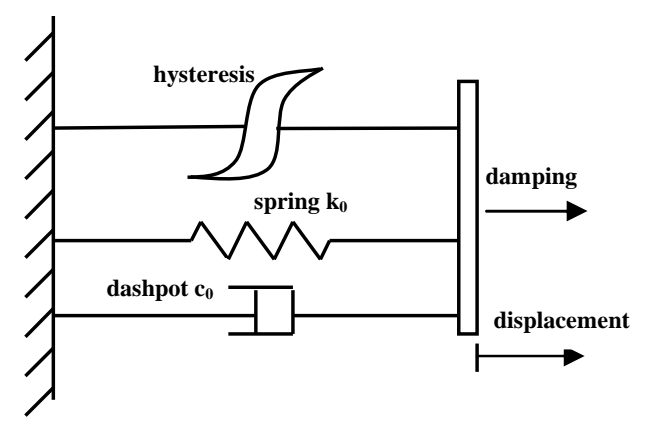

Fig 1. Schematic of the MR damper 


\section{CONTROL OF BUILDING STRUCTURE}

Consider the civil structure with n-storey subjected to earthquake excitation $\ddot{x}_{g}(t)$ as shown in Fig. 2. Assume that a control system installed at the structure consists of MR dampers, controller and current driver. When the structure is influenced by the earthquake $\ddot{x}_{g}(t)$, the responses to be regulated are the displacements, velocities, and accelerations $(\mathbf{x}, \dot{\mathbf{x}}, \ddot{\mathbf{x}})$ of the structure, where $\mathbf{x}$ is the displacement of the floors. The controller with the current driver will excite the MR dampers and the forces $\mathbf{f}$ will be generated to eliminate the vibration of the structure. The output $\mathbf{y}$ is an $\mathbf{r}$-dimensional vector.

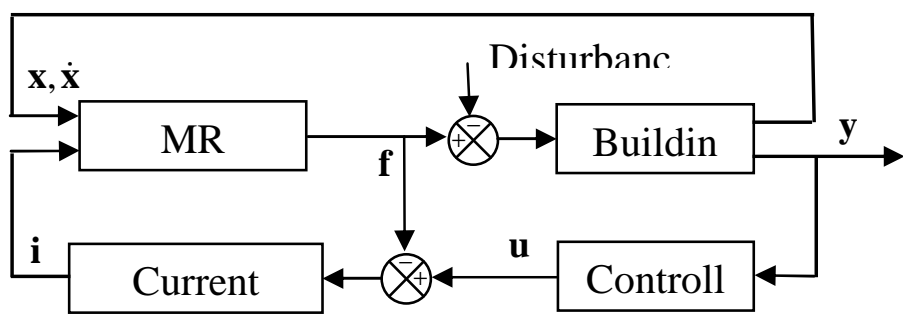

Fig 2. The sliding mode control

The vector equation of motion [2] is presented by

$$
\mathbf{M} \ddot{\mathbf{x}}(t)+\mathbf{C} \dot{\mathbf{x}}(t)+\mathbf{K x}(t)=\Gamma \mathbf{f}(t)+\mathbf{M} \Lambda \ddot{x}_{g}(t),(2)
$$

in which $\mathbf{x}(t)=\left[x_{1} x_{2}, \ldots, x_{n}\right]^{T}, \mathbf{x}(t) \in R^{n}$ is $\quad$ an $\quad \mathrm{n}$ vector of the displacement, $\mathbf{f}(t) \in R^{r}$ is a vector consisting of the control forces, $\ddot{x}_{g}(t)$ is an earthquake excitation acceleration, parameters $\mathbf{M} \in R^{n x n}, \mathbf{C} \in R^{n x n}, \mathbf{K} \in R^{n x n}$ are the mass, damping and stiffness matrices. $\Gamma \in R^{n x r}$ is a matrix denoting the location of $\mathrm{r}$ controllers and $\boldsymbol{\Lambda} \in R^{n}$ is a vector denoting the influence of the earthquake excitation.

Equation (2) can be rewritten in the statespace form as follows:

$$
\begin{aligned}
& \dot{\mathbf{z}}(t)=\mathbf{A z}(t)+\mathbf{B}_{0} \mathbf{f}(t)+\mathbf{E}_{0}(t), \\
& \text { where } \quad \mathbf{z}(t) \in R^{2 n} \text { is } \quad \text { a } \quad \text { state } \\
& \text { vector, } \mathbf{A} \in R^{2 n \times 2 n} \text { is } \quad \text { a } \quad \text { system } \\
& \text { matrix, } \mathbf{B}_{0} \in R^{2 n x r} \text { is a gain matrix and } \\
& \mathbf{E}_{0}(t) \in R^{2 n} \quad \text { is a disturbance vector, }
\end{aligned}
$$

$$
\mathbf{z}(t)=\left[\begin{array}{l}
\mathbf{x} \\
\dot{\mathbf{x}}
\end{array}\right], \mathbf{A}=\left[\begin{array}{cc}
\mathbf{0} & \mathbf{I} \\
-\mathbf{M}^{-1} \mathbf{K} & -\mathbf{M}^{-1} \mathbf{C}
\end{array}\right], \mathbf{B}_{0}=\left[\begin{array}{c}
\mathbf{0} \\
\mathbf{M}^{-1} \Gamma
\end{array}\right], \mathbf{E}_{0}(t)=\left[\begin{array}{c}
\mathbf{0} \\
\mathbf{\Lambda}
\end{array}\right] \ddot{x}_{g}(t) .
$$

From Eq. (1), we can rewrite the equation of the MR damper as follows:

$$
\begin{aligned}
f & =\left(c_{1} \dot{x}+k_{1} x+h_{1}\right) i+\left(c_{0} \dot{x}+k_{0} x+h_{0}\right)+\alpha z \\
& =B i+D,
\end{aligned}
$$


where $\quad B=\left(c_{1} \dot{x}+k_{1} x+h_{1}\right)$ and $D=\left(c_{0} \dot{x}+k_{0} x+h_{0}\right)+\alpha z$ are non-linear functions.

Assume that the MR dampers are installed at floors of the structure to eliminate its vibration, the equations of the MR dampers can be rewritten as follows.

$f_{j}=B_{j}(x) i_{j}+D_{j}(x), j=1,2, \ldots, r$

The force equation can be rewritten as

$$
\mathbf{f}=\mathbf{B}^{*}(x) \mathbf{i}+\mathbf{D}_{0},
$$

where $\mathbf{f}=\left[f_{1}, f_{2}, \ldots, f_{r}\right]^{T}$ is a force vector, $\mathbf{i}=\left[i_{1}, i_{2}, \ldots, i_{r}\right]^{T}$ is a current vector, $\mathbf{D}_{0}=\left[D_{1}(x), D_{2}(x), \ldots, D_{r}(x)\right]^{T}$ can be known as a disturbance vector and $\mathbf{B}^{*}(x) \in R^{r x r}$ is an gain nonlinear function.

Substitution of Eq. (7) into Eq. (3) leads to the following

$$
\mathbf{A z}=\mathbf{B}_{0}\left[\mathbf{B}^{*}(x) \mathbf{i}+\mathbf{D}_{0}(x)\right]+\mathbf{E}_{0}
$$

where $x$ and $t$ has been dropped for clarity.

The state equation can be rewritten as follows

$$
\dot{\mathbf{z}}=\mathbf{A z}+\mathbf{B i}+\mathbf{E},
$$

where $\mathbf{B}=\mathbf{B}_{0} \mathbf{B}^{*}, \quad \mathbf{B}^{*}(x) \in R^{2 n x r}$ is an unknown gain matrix and $\mathbf{E}=\mathbf{B}_{0} \mathbf{D}_{0}+\mathbf{E}_{0}$ is not exactly known, but estimated as $\|\mathbf{E}\|_{p}=\rho$, the vector norm $\|\mathbf{E}\|_{p}$ is defined as $\|\mathbf{E}\|_{p}=\left(\sum_{i}\left|e_{i}\right|^{p}\right)^{\frac{1}{p}}, p=1,2, \ldots$.
Assume that each MR damper can be installed at each floor of the structure, we can rewrite the matrix $\mathbf{B}$ with diagonal elements $B_{j j}, j=1,2, \ldots, r$ as

$$
\mathbf{B}=\left[\begin{array}{c}
\mathbf{0} \\
\mathbf{b}_{r r}
\end{array}\right] \text {. }
$$

Assumption: the bounds of the elements of $\mathbf{B}$ are all known as $\hat{B}_{j j}, j=1,2, \ldots, r$. The matrix $\hat{\mathbf{B}}$ is definite and invertible and is defined as

$$
\hat{\mathbf{B}}=\left[\begin{array}{c}
\mathbf{0} \\
\hat{B}_{r r}
\end{array}\right] .
$$

\section{SLIDING MODE CONTROL}

The main advantage of the SMC is known to be robust against variations in system parameters or external disturbance. The selection of the control gain $\eta_{a}$ is related to the magnitude of uncertainty to keep the trajectory on the sliding surface.

In the design of the sliding surface, the external disturbance are neglected, however it is taken into account in the design of controllers. For simplicity, let $\sigma=0$ be an $r$ dimensional sliding surface consisting of a linear combination of state variables, the surface [14] is expressed as

$$
\sigma=\mathbf{S z},
$$

taking derivative of the function $\sigma$, we obtain as

$$
\dot{\sigma}=\mathbf{S} \dot{\mathbf{z}},
$$


in which $\sigma \in R^{\mathrm{r}}$ is a vector consisting of $\mathrm{r}$ sliding variables, $\sigma_{1}, \sigma_{2}, \ldots, \sigma_{\mathrm{r}}$ and $\mathbf{S} \in R^{\mathrm{rx} 2 \mathrm{n}}$ is a matrix to be determined such that the motion on the sliding surface is stable.

In the case of a full state feedback, either the method of LQR or pole assignment will be used to design the controllers. The design of the sliding surface is obtained by minimizing the integral of the quadratic function of the state vector.

The SMC output $\mathbf{i}$ consists of two components as

$$
\mathbf{i}=\mathbf{i}_{e}+\mathbf{i}_{s},
$$

where $\mathbf{i}_{e}, \mathbf{i}_{s}$ are the equivalent control output and the switching control output, respectively.

A cost function $[17,18]$ is defined as

$$
\mathbf{J}=\int \mathbf{z}^{T} \mathbf{Q} \mathbf{z} d t,
$$

after determining the cost matrix $\mathbf{Q}$ and the LQR gain $\mathbf{F}$ in $[14,16]$, the equivalent controller $\mathbf{i}_{e}$ will be found as follows

$$
\mathbf{i}_{e}=-\mathbf{F z} .
$$

To obtain the design of the controllers, a Lyapunov function is considered

$$
V=\frac{1}{2} \sigma^{2},(16 \mathrm{a})
$$

taking derivative of the Lyapunov function, we obtain

$$
\dot{V}=\sigma^{T} \dot{\sigma} . \quad(16 \mathrm{~b})
$$

Substitution of Eqs. (9) and (12b) into Eq. (16b) leads to the following

$$
\dot{V}=\sigma^{T} \dot{\sigma}=\sigma^{T} \mathbf{S}(\mathbf{A z}+\mathbf{B i}+\mathbf{E}),
$$

in which $\mathbf{E}$ can be neglected in designing the equivalent controller. For $\dot{V}=\sigma^{T} \dot{\sigma}=0$, we can rewrite Eq. (17) as

$$
\sigma^{T} \mathbf{S}\left(\mathbf{A z}+\mathbf{B} \mathbf{i}_{e}\right)=0,(18)
$$

according to the above Assumption, the matrix $\mathbf{B}$ is unknown, its estimation $\hat{\mathbf{B}}$ can be used to construct the equivalent controller $\hat{\mathbf{i}}_{e}$, the controller output is presented as follows

$$
\hat{\mathbf{i}}_{e}=-(\mathbf{S} \hat{\mathbf{B}})^{-1} \mathbf{S A z} \text {. }
$$

To design the switching controller, according to the Lyapunov condition, the system is stable on the sliding surface if and only if $\dot{V}<0$.

Substitution of Eqs. (9), (12b) and (13) into Eq. (16b) leads to the following

$$
\dot{V}_{a}=\sigma^{T} \mathbf{S}(\mathbf{A z}+\hat{\mathbf{B}} \mathbf{i}+\mathbf{E})=\sigma^{T} \mathbf{S}\left(\mathbf{A z}+\hat{\mathbf{B}} \hat{\mathbf{i}}_{e}\right)+\sigma^{T} \mathbf{S}\left(\hat{\mathbf{B}} \hat{\mathbf{i}}_{s}+\mathbf{E}\right),
$$

where $\sigma^{T} \mathbf{S}\left(\mathbf{A z}+\hat{\mathbf{B}} \hat{\mathbf{i}}_{e}\right)=0 \quad$ is the equivalent controller.

The equation is rewritten as

$$
\dot{V}_{a}=\sigma^{T} \mathbf{S}\left(\hat{\mathbf{B}}_{s}+\mathbf{E}\right)=\sigma^{T} \mathbf{S}\left(\hat{\mathbf{B}} \hat{\mathbf{i}}_{s}+\rho\right)
$$


$\mathbf{S}\left(\hat{\mathbf{B}} \hat{\mathbf{i}}_{s}+\rho\right)=-\eta_{a} \operatorname{sign}(\sigma), \quad(22 \mathrm{a})$

then, the possible switching controller is depicted by

$\hat{\mathbf{i}}_{s}=-(\mathbf{S} \hat{\mathbf{B}})^{-1}\left(\eta_{a} \operatorname{sign}(\sigma)+\mathbf{S} \rho\right) .(22 \mathrm{~b})$

The SMC output involves two components $\mathbf{i}_{e}$ and $\mathbf{i}_{s}$ used to drive the trajectories of the controlled system on the sliding surface. The equivalent control component $\mathbf{i}_{e}$ guarantees the states on the sliding surface and the nonlinear switched feedback control component $\mathbf{i}_{s}$ is used to compensate the disturbance. The magnitude of $\eta_{a}>0$ depends on the expected uncertainty in the external excitation or parameter variation so that the system is stable on the sliding surface.

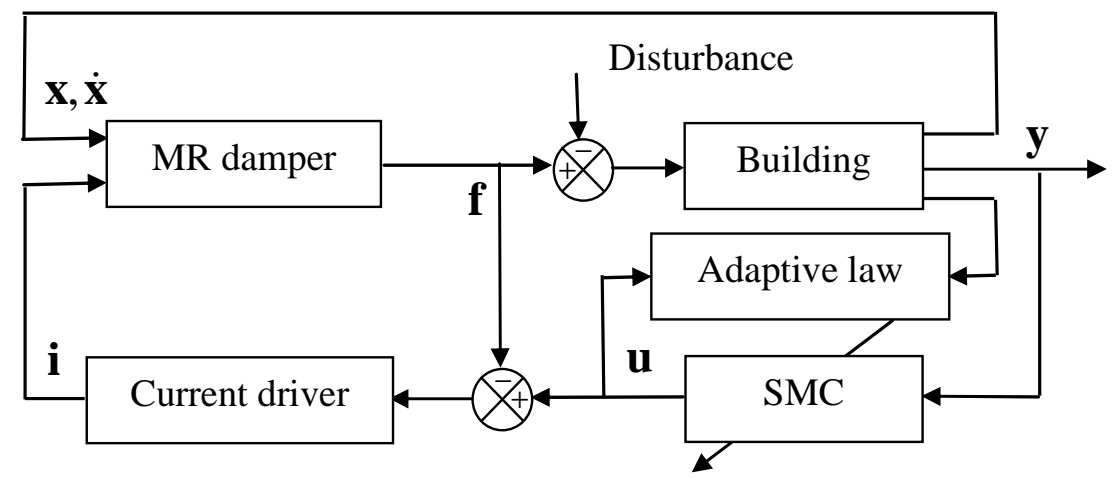

Fig. 3: The adaptive sliding mode control

\section{ADAPTIVE SLIDING MODE CONTROL}

As shown in Fig. 1, this control system proposed with a parameter estimator is the adaptive controller, which is based on the control parameters. There is a mechanism for adjusting these parameters on-line based on signals in the system. In the building structure, the so-called self-tuning adaptive control method is proposed as in Fig. 3. According to the figure, the sliding mode control is used to constrain trajectories on the sliding surface so that the system is robust and stable onto that surface. With the adaptive SMC, if the plant parameters are not known, it is intuitively reasonable to replace them by their estimated values, as provided by a parameter estimator. Thus, a self-tuning controller is a controller, which performs simultaneous identification of the unknown plant.

We now show how to derive an adaptive law to adjust the controller parameters such that the estimated equivalent control $\hat{\mathbf{i}}_{e}$ can optimally approximate the equivalent control of the SMC, given the unknown function $\mathbf{B}$. We construct the switching control to guarantee the system's stability by the Lyapunov theory so that the ultimately bounded tracking is accomplished.

We choose the control law as follows:

$$
\mathbf{i}=\hat{\mathbf{i}}_{e}+\hat{\mathbf{i}}_{s},
$$


where $\mathbf{i}$ is the SMC output and we use an estimation law to generate the estimated parameter $\hat{\mathbf{B}}$ as assumed.
We will further determine the adaptive law for adjusting those parameters.

Consider the equation of motion as follows:

$$
\dot{\mathbf{z}}=\mathbf{A z}+\mathbf{B i}+\mathbf{E}=\mathbf{A z}+\mathbf{B}\left(\hat{\mathbf{i}}_{\mathbf{e}}+\hat{\mathbf{i}}_{s}\right)+\mathbf{E}+\hat{\mathbf{B}} \hat{\mathbf{i}}_{\mathbf{e}}-\hat{\mathbf{B}}_{\hat{\mathbf{i}}_{\mathbf{e}}},
$$

substitution of Eq. (19) into Eq. (24) leads to as

$$
\dot{\mathbf{z}}=(\mathbf{B}-\hat{\mathbf{B}}) \hat{\mathbf{i}}_{e}+\mathbf{B} \hat{\mathbf{i}}_{s}+\mathbf{E}
$$

Assume that we have an estimated error function as follows:

$$
\tilde{\mathbf{B}}=\mathbf{B}-\hat{\mathbf{B}}
$$

$$
\begin{aligned}
\dot{V}_{b} & =\sigma^{T} \mathbf{S}\left(\tilde{\mathbf{B}} \hat{\mathbf{i}}_{e}+\mathbf{B} \hat{\mathbf{i}}_{s}+\mathbf{E}\right)+(\tilde{\mathbf{B}} \gamma)^{T}(\dot{\tilde{\mathbf{B}}} \gamma) \\
& =\sigma^{T} \mathbf{S} \tilde{\mathbf{B}} \hat{\mathbf{i}}_{e}+(\tilde{\mathbf{B}} \gamma)^{T}(\dot{\tilde{\mathbf{B}}} \gamma)+\sigma^{T} \mathbf{S}\left(\mathbf{B}_{\hat{\mathbf{i}}_{s}}+\mathbf{E}\right)
\end{aligned}
$$

The tracking error allows us to choose the adaptive law for the parameter $\hat{\mathbf{B}}$ as

Substituting Eq. (26) into Eq. (25), we can rewrite the equation of motion as follows:

$$
\dot{\mathbf{z}}=\tilde{\mathbf{B}} \hat{\mathbf{i}}_{e}+\mathbf{B} \hat{\mathbf{i}}_{s}+\mathbf{E}
$$

Now, consider the Lyapunov function candidate

$$
V_{b}=\frac{1}{2}\left[\sigma^{T} \sigma+(\tilde{\mathbf{B}} \gamma)^{T}(\tilde{\mathbf{B}} \gamma)\right]
$$

where $\gamma$ is a positive constant gain of the adaptive algorithm.

Taking the derivative of the Lyapunov function in [17], we can obtain as

$$
\dot{V}_{b}=\left[\sigma^{T} \dot{\sigma}+(\tilde{\mathbf{B}} \gamma)^{T}(\dot{\tilde{\mathbf{B}}} \gamma)\right]
$$

Substitution of Eqs. (12b) and (27) into Eq. (29) leads to as follows:

$$
\dot{\hat{\mathbf{B}}}=\left[(\tilde{\mathbf{B}} \gamma)(\tilde{\mathbf{B}} \gamma)^{T}\right]^{-1}(\tilde{\mathbf{B}} \gamma) \sigma^{T} \tilde{\mathbf{B}} \mathbf{S} \hat{\mathbf{i}}_{e} \gamma^{T}\left(\gamma \gamma^{T}\right)^{-1}
$$

From Eq. (26), the following relation is used $\dot{\tilde{\mathbf{B}}}=-\dot{\hat{\mathbf{B}}}$ for $\dot{\mathbf{B}}=0$, we obtain as

$$
\dot{\tilde{\mathbf{B}}}=-\left[(\tilde{\mathbf{B}} \gamma)(\tilde{\mathbf{B}} \gamma)^{T}\right]^{-1}(\tilde{\mathbf{B}} \gamma) \sigma^{T} \tilde{\mathbf{B}} \mathbf{\hat { \mathbf { i } }} \hat{\boldsymbol{i}} \gamma^{T}\left(\gamma^{T}\right)^{-1}
$$

then, the Lyapunov equation is written as follows:

$$
\dot{V}_{b}=\sigma^{T} \mathbf{S}\left(\mathbf{B} \hat{\mathbf{i}}_{s}+\mathbf{E}\right),
$$

according to the above estimation $\|\mathbf{E}\|_{p}=\rho$ and Assumption $\hat{\mathbf{B}}$, the equation can be rewritten as follows:

$$
\dot{V}_{b}=\sigma^{T} \mathbf{S}\left(\hat{\mathbf{B}} \hat{\mathbf{i}}_{s b}+\rho\right)
$$


With the adaptive law in Eq. (31), the asymptotic stability of the adaptive sliding mode control system can be guaranteed.

Such that $\dot{V}_{b}<0$, we can write as follows:

$$
\mathbf{S}\left(\hat{\mathbf{B}}_{s b}+\rho\right)=-\eta_{b} \operatorname{sign}(\sigma),(33 \mathrm{a})
$$

the switching controller can be expressed as follows:

$$
\hat{\mathbf{i}}_{s b}=-(\mathbf{S} \hat{\mathbf{B}})^{-1}\left[\eta_{b} \operatorname{sign}(\sigma)+\mathbf{S} \rho\right]
$$

The magnitude of $\eta_{b}>0$ depends on the expected uncertainty in the external disturbance or parameter variation so that the system is stable on the sliding surface.

Combine Eq. (22b) and Eq. (33b), we should take

$$
\eta=\max \left\{\eta_{a}, \eta_{b}\right\}
$$

such that the system globally satisfies to be stable on the sliding surface.

\section{SIMULATION RESULTS}

Consider the structure of a five-storey building model which has two MR dampers installed at the first floor and the second floor as shown in Fig. 4, $\mathbf{x}=\left[x_{1}, x_{2}, x_{3}, x_{4}, x_{5}\right]^{T}$ is the displacement vector, $f_{1}$ and $f_{2}$ are forces of these MR damper and parameters $m_{i}, k_{i}, c_{i}(i=1,2, \ldots, 5)$ are mass, damping and stiffness coefficients, respectively.

The corresponding matrices $\mathbf{M}, \mathbf{C}$ and $\mathbf{K}$ are as follows:

$\mathbf{M}=\left[\begin{array}{ccccc}337 & 0 & 0 & 0 & 0 \\ 0 & 330 & 0 & 0 & 0 \\ 0 & 0 & 330 & 0 & 0 \\ 0 & 0 & 0 & 330 & 0 \\ 0 & 0 & 0 & 0 & 337\end{array}\right] k g$

$\mathbf{C}=\left[\begin{array}{ccccc}225 & -157 & 26 & -7 & 2 \\ -157 & 300 & -126 & 25 & -4 \\ 26 & -126 & 299 & -156 & 16 \\ -7 & 25 & -156 & 279 & -125 \\ 2 & -4 & 16 & -125 & 125\end{array}\right] \frac{N s}{m}$,

$\mathbf{K}=\left[\begin{array}{ccccc}3766 & -2869 & 467 & -234 & 27 \\ -2869 & 5149 & -2959 & 446 & -70 \\ 467 & -2959 & 5233 & -2836 & 280 \\ -234 & 446 & -2836 & 4763 & -2277 \\ 27 & -70 & 280 & -2277 & 2052\end{array}\right] \frac{k N}{m}$

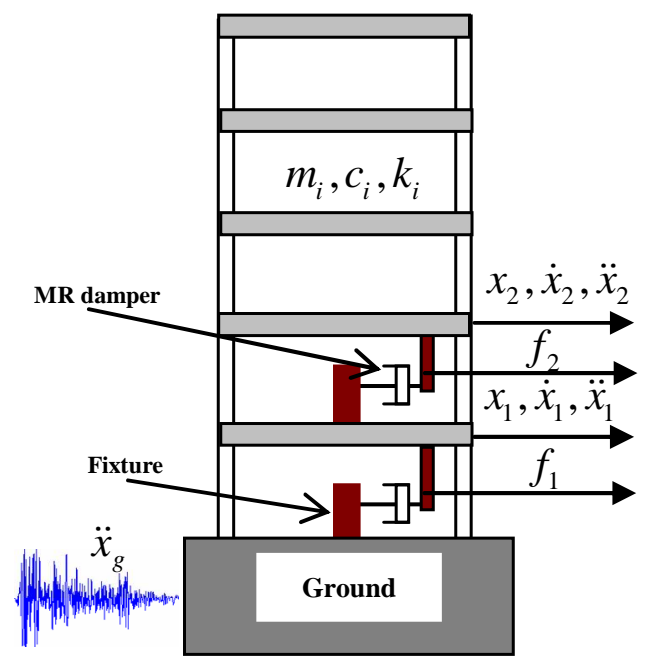

Fig 4. The building model with 2 MR dampers 
The coefficents $\mathbf{M}, \mathbf{C}$ and $\mathbf{K}$ were collected from a 5-storey model at University of Technology, Sydney (UTS). Therefore, according to Equation (2) and (3), when there is an earthquake, the force $\mathbf{f}$ will be just changed in order to reduce the storey displacement. While the coefficents $\mathbf{M}, \mathbf{C}$ and $\mathbf{K}$ will not change and are often determined based on storey structures. For example, if the building structute is 5 storeys, their matrices are as shown in Equations (35), (36) and (37) and if it is a 3-storey building, the coefficents $\mathbf{M}, \mathbf{C}$ and $\mathbf{K}$ will be matrices of $3 \times 3$.

Based on Equation (3) and (5), accelerations $\ddot{x}_{1}$ and $\ddot{x}_{2}$ corresponding to these MR dampers installed at the building are

$$
\begin{aligned}
\ddot{x}_{1} & =A_{01}+B_{1} f_{1}+E_{01} \\
& =A_{01}+B_{1}\left(h_{1} i_{1}+D_{1}\right)+E_{01} \\
& =A_{01}+B_{1} h_{1} i_{1}+B_{1} D_{1}+E_{01} \\
& =A_{01}+B_{1} h_{1} i_{1}+E_{1},
\end{aligned}
$$

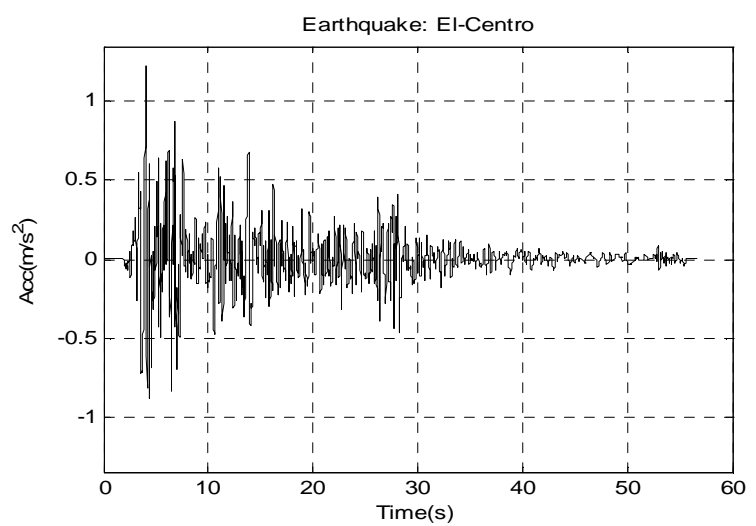

Fig 5. Earthquake record: El-Centro

$$
\begin{aligned}
\ddot{x}_{2} & =A_{02}+B_{2} f_{2}+E_{02} \\
& =A_{02}+B_{2}\left(h_{2} i_{2}+D_{2}\right)+E_{02} \\
& =A_{02}+B_{2} h_{2} i_{2}+B_{2} D_{2}+E_{02} \\
& =A_{02}+B_{2} h_{2} i_{2}+E_{2},
\end{aligned}
$$

where

$A_{01}=-m_{1}^{-1}\left(\left(k_{1}+k_{2}\right) x_{1}-k_{2} x_{2}+\left(c_{1}+c_{2}\right) \dot{x}_{1}-c_{2} \dot{x}_{2}\right)$ $A_{02}=-m_{2}^{-1}\left(\left(k_{1}+k_{2}\right) x_{2}-k_{2} x_{1}+\left(c_{1}+c_{2}\right) \dot{x}_{2}-c_{2} \dot{x}_{1}\right)$ and $E_{1}=B_{1} D_{1}+E_{01}$ and $E_{2}=B_{2} D_{2}+E_{02}$ are the first-floor and second-floor disturbances, respectively, in which $B_{1}$ and $B_{2}$ are current gains.

Control parameters are given in Table $\mathbf{1}$, in which $\rho$ and $\gamma$ are the estimated vector norm and the positive constant gain.

Table 1. Control parameters

\begin{tabular}{|c|c|c|c|}
\hline \multirow{2}{*}{ SMC } & SMC & \multicolumn{2}{|c|}{ Adaptive SMC } \\
\cline { 2 - 4 } & $\rho$ & $\rho$ & $\gamma$ \\
\hline 1 & 650 & 500 & 1 \\
\hline 2 & 1.5 & 0.45 & {$[0.1 ;-0.5]$} \\
\hline
\end{tabular}

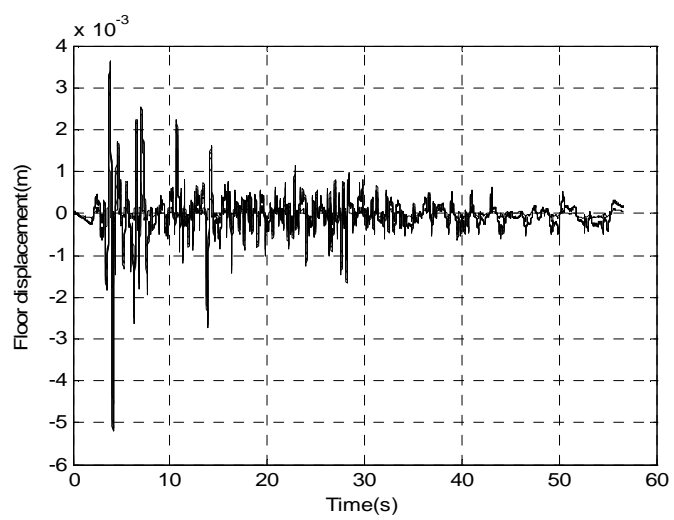

Fig 9. Floor displacement using SMC-2 MR dampers 


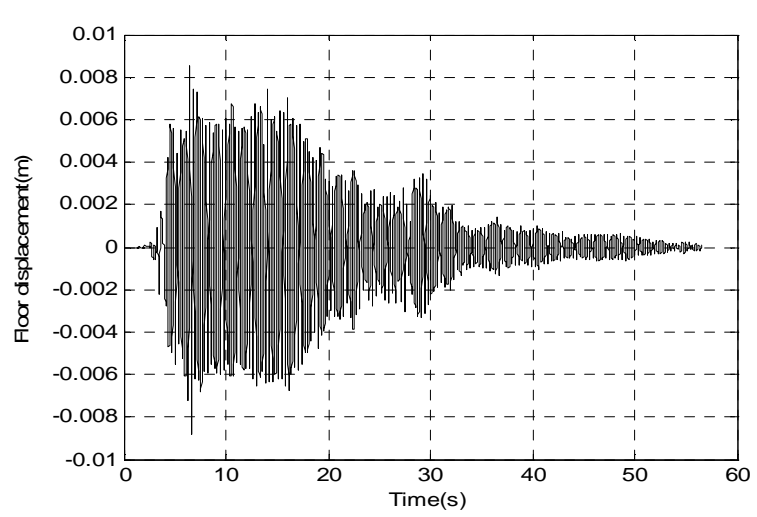

Fig 6. Floor displacement-uncontrolled

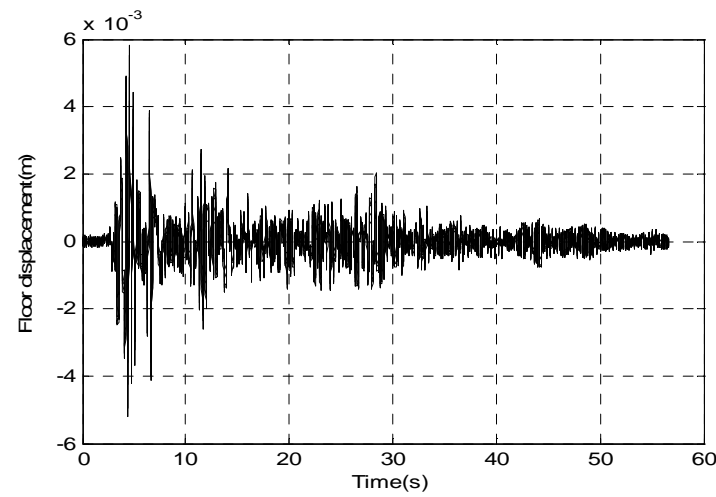

Fig 7. Floor displacement using SMC-1 MR damper

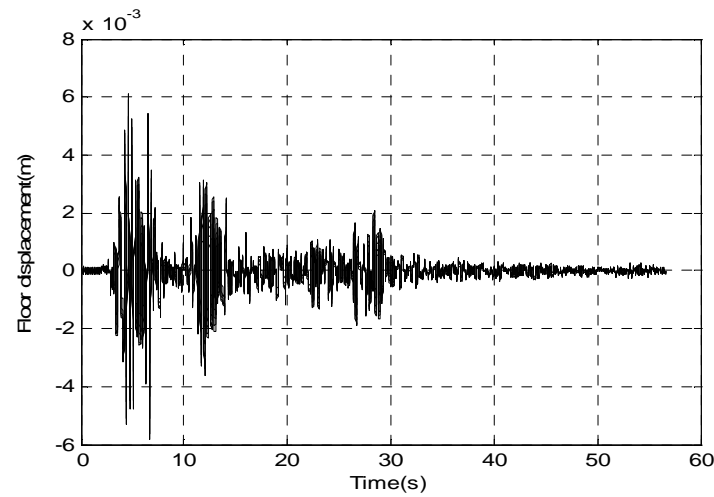

Fig 8. Floor displacement using ASMC-1 MR damper

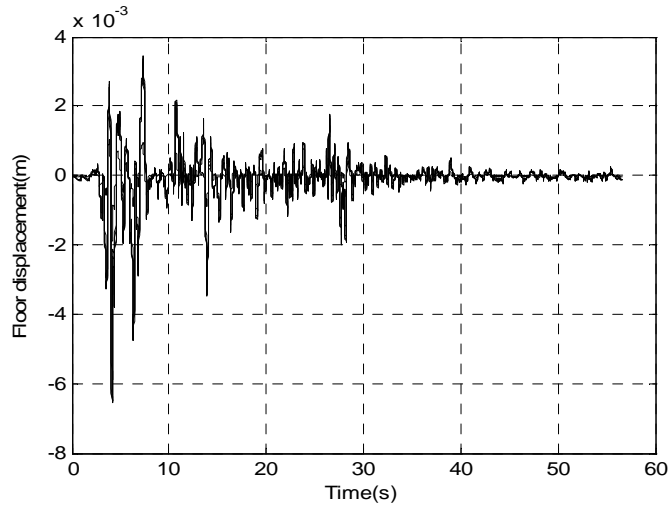

Fig 10. Floor displacement using ASMC-2 MR dampers

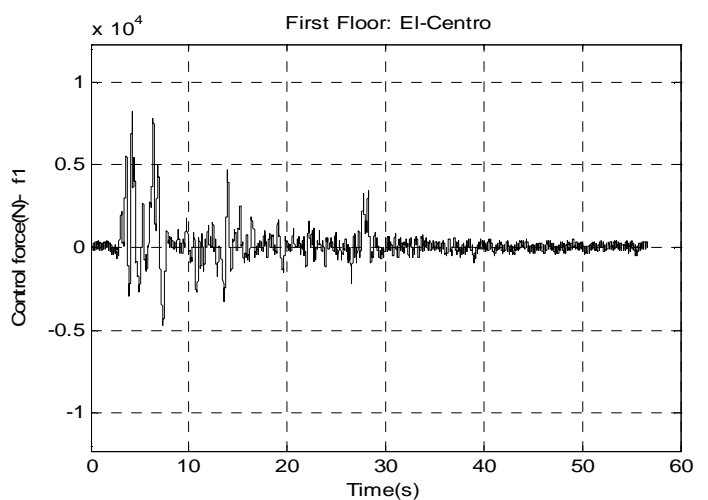

Fig 11. Control force of MR damper at first-floor

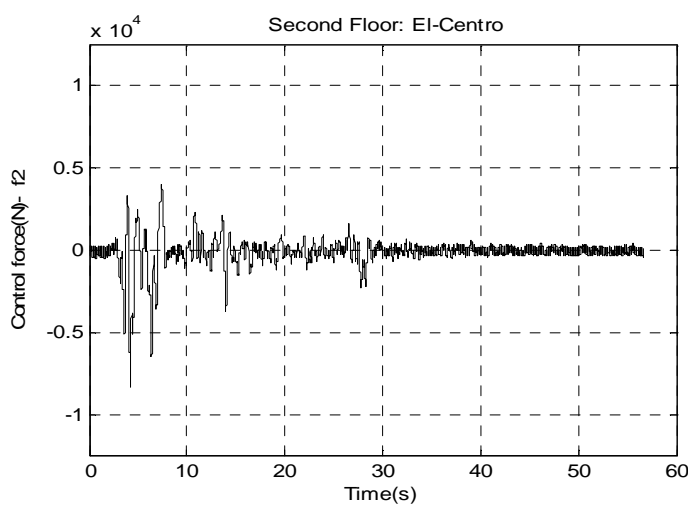

Fig 12. Control force of MR damper at second-floor 
Time responses of floor displacements are shown in the Figs 5-12, in which Fig 5 is the El-Centro earthquake record, Fig 6 shows the floor displacement without control. In Fig 7 and Fig $\mathbf{8}$ are the floor displacements using SMC and adaptive sliding mode control (ASMC) methods for one MR damper installed at the $1^{\text {st }}$ floor, respectively. In two cases, the floor displacement using the ASMC shows better simulation result than that using the SMC. The results of displacements at the second as shown in Fig 9 and Fig 10 using the SMC and the ASMC with MR dampers are better than that at the first. Fig 11 and Fig 12 are control forces $f_{1}, f_{2}$ of the MR dampers installed at floor-1 and floor-2. In addition,

Table 2 summarises numerical results of cases such as uncontrolled, SMC-1 MR damper, ASMC-1 MR damper, in which the SMC-1 MR damper is installed at level-1 and the SMC-2 MR damper is of level-2. For similarity, the ASMC-1 MR damper and the ASMC-2 MR damper can be replaced the SMC-1 MR damper and the SMC-2 MR damper for the comparison. Moreover, the different control forces of the first and second floors were shown as in Fig 11 and Fig 12 in order to illustrate that the second floor is less the displacement than the first floor.

Table 2. Floor displacements from different controls

\begin{tabular}{|c|c|c|c|c|c|c|c|c|c|c|}
\hline & \multicolumn{2}{|c|}{ Uncontrolled } & \multicolumn{2}{|l|}{ SMC-1 damper } & \multicolumn{2}{c|}{$\begin{array}{c}\text { ASMC-1 } \\
\text { damper }\end{array}$} & \multicolumn{2}{l|}{ SMC-2 dampers } & \multicolumn{2}{c|}{$\begin{array}{c}\text { ASMC-2 } \\
\text { dampers }\end{array}$} \\
\hline $\begin{array}{c}\text { Floo } \\
\mathbf{r} \\
\text { No. }\end{array}$ & $\begin{array}{c}\text { Max } \\
(\mathrm{mm})\end{array}$ & $\begin{array}{c}\text { RMS } \\
(\mathrm{mm})\end{array}$ & $\begin{array}{c}\text { Max } \\
(\mathrm{mm})\end{array}$ & $\begin{array}{c}\text { RMS } \\
(\mathrm{mm})\end{array}$ & $\begin{array}{c}\text { Max } \\
(\mathrm{mm})\end{array}$ & $\begin{array}{c}\text { RMS } \\
(\mathrm{mm}\end{array}$ & $\begin{array}{c}\text { Max } \\
(\mathrm{mm})\end{array}$ & $\begin{array}{c}\text { RMS } \\
(\mathrm{mm})\end{array}$ & $\begin{array}{c}\text { Max } \\
(\mathrm{mm})\end{array}$ & $\begin{array}{c}\text { RMS } \\
(\mathrm{mm} \\
)\end{array}$ \\
\hline $\mathbf{1}$ & 6.3 & 2.2 & 3.0 & 0.20 & 3.3 & 0.23 & 2.8 & 0.40 & 2.5 & 0.35 \\
\hline $\mathbf{2}$ & 9.0 & 1.7 & 3.8 & 0.41 & 3.4 & 0.28 & 3.0 & 0.50 & 3.1 & 0.45 \\
\hline $\mathbf{3}$ & 12.0 & 2.0 & 4.0 & 0.38 & 3.2 & 0.27 & 3.3 & 0.60 & 3.4 & 0.50 \\
\hline $\mathbf{4}$ & 13.5 & 2.2 & 5.1 & 0.39 & 5.0 & 0.30 & 4.3 & 0.60 & 4.2 & 0.50 \\
\hline $\mathbf{5}$ & 13.5 & 2.3 & 5.1 & 0.37 & 5.0 & 0.32 & 4.2 & 0.52 & 4.1 & 0.47 \\
\hline
\end{tabular}

\section{CONCLUSION AND DISCUSSION}

A sliding mode controller (SMC) has been applied to the control of a building structure using MR dampers installed at each floor. A modified controller using adaptive algorithm is proposed for the building structures. The stability of the building structure using the adaptive SMC (ASMC) as shown in Fig 8 and Fig 10 is proven based on the Lyapunov function candidate. Simulation results when applying these controllers to a 5-storey model have illustrated the effectiveness of the proposed method. In practicular, the comparison between uncontrolled and controlled floor displacements as shown in Fig 6 (uncontrolled) and Figs 7-10 (controlled) show that the floors installed with RM dampers using ASMC method will be better than that using SMC method. Moreover, Table 2 shows the displacement numbers of the first and second storeys using different cases such as 
uncontrolled, SMC-1 damper, ASMC-1 damper, SMC-2 damper and SMC-2 damper, in which amplitudes of controlled methods using SMC damper and ASMC damper are better than that of uncontrolled method. In this Table
2, max and RMS values are also shown for the comparison of the displacements. In addition, numbers show that storeys using ASMC MR dampers are more stable than that using SMC MR dampers.

\title{
ĐIỀU KHIỂN KIỂU TRƯợT THÍCH NGHI CHO CÂU TRÚC TÒA NHÀ SỦ DỤNG GIẢM XÓC MR
}

\author{
Nguyễn Thanh Hải ${ }^{(1)}$, Dương Hoài Nghĩa ${ }^{(2)}$, Lâm Quang Chuyên ${ }^{(3)}$, \\ (1) Trường Đại Học Quốc tế, ĐHQG-HCM \\ (2) Trường Đại Học Bách Khoa, ĐHQG-HCM \\ (3) Trường Cao Đẳng Công Thương, Tp.HCM
}

TÓM TĂT: Trong bài báo này, điều khiển kiểu trượt cho nhũng công trình xây dựng sủ dụng bộ giảm xóc MR (Magnetorheological) được đề xuất cho việc giảm rung của tòa nhàkhi có động. Đầu tiên, hệ thống điều khiển kiểu trượt gián tiếp cho nhũng cấu trúc xây dựng được thiết kế. Tuy nhiên, để giải quyết vấn đề phi tuyến được tạo ra bởi điều khiển gián tiếp, một luật thích nghi cho điều khiển kiểu trượt được áp dụng để tính toán sụ bền vũng của bộ điều khiển này. Tiếp theo, bộ điều khiển kiểu truợt thích nghi được tính toán cho sụ ổn định của hệ thống dựa vào lý thuyết Lyapunov. Cuối cùng, nhũng kết quả mô phỏng cho thấy sụ hiệu quả của bộ điều kiển kiến nghị.

\section{REFERENCES}

[1] Phạm Nhân Hòa, Chu Quốc Thắng, Đánh giá hiệu quả Của Hệ Cản $M a$ Sát Biến Thiến Với Công Trình Chịu Tải Trọng Động Đất, Science and Technology Development, Vol. 11, Số 12 (2008).

[2] Phạm Nhân Hòa, Chu Quốc Thắng, Các Phưong Án Sủ Dụng Hệ Cản Ma Sát Biến Thiến Trong Kết Cấu 9 Tầng,
Science and Technology

Development, Vol. 11, Số 9 (2008).

[3] Nguyễn Quang Bảo Phúc, Phạm Nhân Hòa, Chu Quốc Thắng, So Sánh Khả Năng Giam Chấn Của Hệ Cản Có Độ Cưng Thay Đổi Với Hệ Cản Ma Sát Biến Thiến, Science and Technology Development, Vol. 12, Số 8 (2009).

[4] B. F. Spenser Jr., S. J. Dyke, M. K. Sian and J. D. Carlson, Phenomenological model for 
magnetorheological dampers, J. of Engineering Mechanics, 230-238 (1997).

[5] Nguyễn Minh Hiếu, Chu Quốc Thắng, Điều Khiển Hệ Cản Bán Chủ Động RM VớiCác Giải Thuật Khác Nhau Của Công, Science and Technology Development, Vol. 12, Số 4 (2009).

[6] G. Bossis and S. Lacis, Magnetorheological fluids, J. of Magnetism and Magnetic Materials, Vol. 252, 224-228 (2002).

[7] S. L. Djajakesukuma, B. Samali and H. Nguyen, Study of a semi-active stiffness damper under various earthquake inputs, Earthquake Eng. Structural Dynamics, Vol. 31, 17571776 (2002).

[8] T. Butz and O. von. Stryk, Modelling and simulation of electro- and magnetorheological fluid dampers, Applied Mathematics and Mechanics (2002).

[9] R. Stanway, J. L. Sproston and N. G. Stevens, Non-linear identification of an Electro-rheological vibration damper, IFAC Identification and System Parameter Estimation, pp. 195-200 (1985).

[10] R. Stanway, J. L. Sproston and N. G. Stevens, Non-linear modelling of an electro-rheological vibration damper, J. Electrostatics, Vol. 20, 167-173 (1987).
[11]Y. K. Wen, Method of random vibration of hysteretic systems, Journal of Engineering Mechanics Division, ASCE, Vol. 102, 249-263 (1976).

[12] S. J. Dyke, B. F. Spencer Jr, M. K. Sain and J. D. Carlson, Modelling and control of magnetorheological dampers for seismic response reduction, Smart Material Structure, Vol 5, 565-575 (1996).

[13] N. M. Kwok, Q. P. Ha, T. H. Nguyen, J. Li and B. Samali, A novel hysteretic model for magnetorheological fluid dampers and parameter identification using particle swarm optimization, Sensors and Actuators A (2006).

[14] R. A. DeCarlo, S. H. Zak and R. A. Matthews, Variable structure control of nonlinear multivariable system: A tutorial, IEEE, Vol. 76, No. 3, 212232 (1988).

[15] V. Utkin, J. Guldner, and J. Shi, Sliding Mode Control in electromechanical systems, Taylor and Francis, UK (1999).

[16]C. Edwards and S. K. Spurgeon, Sliding mode control: theory and applications, Taylor and Francis, London, UK (1998).

[17] J. N. Yang, J. C. Wu, A. K. Agrawal and Z. Li, Sliding mode control for seismic-excited linear and nonlinear civil engineering structures, Technical Report NCEER-94-0017, University 
of California, Dept. of Civil Engineering, Irvine, California (1994).

[18]Q. P. Ha, J. Li, G. Hong and B. Samali, Active structural control using dynamic output feedback sliding mode, Proc. 2001 Australian Conf. on Robotics and Automation, Sydney, Nov 2001, 20-205 (2001).

[19]R. Adhikari and H. Yamaguchi, Sliding mode control of building with $A T M D$, Earthquake Engineering and Structural Dynamics, Vol. 26, 409422 (1997).

[20] N. M. Kwok, T. H. Nguyen, Q. P. Ha, J. Li and B. Samali, MR damper structure control using a multi-level sliding mode controller, Australian Earthquake Engineering Society Conference, Albury Australia, 10.110.7 (2005).
[21] Stoline, J. J. E., and W. Li, Applied nonlinear control, Prentice-Hall, Englewood Cliffs, New Jersey (1991).

[22]F. Mark, S. Csaba, and R. Eric, Performance of nonlinear approximate adaptive controllers, John Wiley and Sons, Ltd (2003).

[23] R. J. Wai, J. D. Lee, and L. J. Chang, Development of adaptive sliding mode control for nonlinear dual-axis inverted-pendulum system, EEE/ASME International Conference on Advanced Intelligent Mechatronics, Vol. 2, 815 - 820 (2003).

[24]R. J. Wai, Adaptive sliding-mode control for induction servomotor drive, IEE Electric Power Applications, Vol. 147, Issue 6, 553562 (2000). 